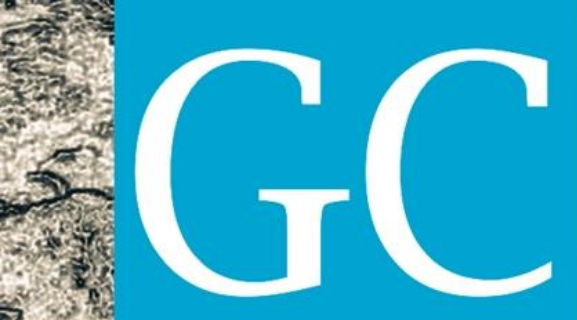

Revista Nacional de

Gerenciamento de Cidades

\title{
Análise de teorias e práticas relativas à governança ambiental de recursos hídricos
}

Analysis of theories and practices relating to environmental water resource governance

Análisis de teorías y prácticas relacionadas com gobierno medioambiental de recursos hídricos

José Freitas do Nascimento

Engenheiro Civil, Mestrando do Programa de Gestão

Ambiental e Sustentabilidade - Geas, Uninove, Brasil jfnasc2018@gmail.com

Ana Paula Branco do Nascimento Bióloga, Professora Doutora do Programa de Gestão Ambiental e Sustentabilidade - Geas, Uninove, Brasil apbnasci@yahoo.com.br

Heidy Rodriguez Ramos Administradora, Professora Doutora do Programa de Gestão Ambiental e Sustentabilidade - Geas, Uninove, Brasil heidyr@gmail.com 


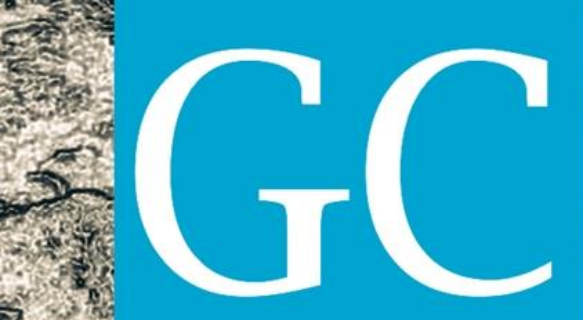

Revista Nacional de

Gerenciamento de Cidades

\section{ANÁLISE E DISCUSSÃO DOS RESULTADOS}

Após a avaliação de cada trabalho com base na leitura de título e resumo foi possível perceber que a questão da governança já foi discutida por diversos autores, porém visões e direcionamentos distintos que mostra que há muito ainda a ser estudado.

\subsection{ANÁLISE DA REVISÃO DA LITERATURA}

Com base na planilha de registros foi possível levantar alguns dados estatísticos que apresentamos a seguir:

$\checkmark \quad$ Quanto aos autores $\rightarrow$ Foram vários autores diferentes encontrados na pesquisa, seja como autor principal ou colaborador, o que possível destacar é que Pedro Roberto Jacobi e Ana Paula Fracalanza tiveram três trabalhos entre os identificados na pesquisa, além disso, foram citados em trabalhos de outros autores mais de uma vez (apontando que se trata de especialistas no tema), figura 3.

Figura 3: Referência dos Autores mais Citados

JACOB I, Pedro Roberto. Universidade de São Paulo. São Paulo, Brasil. prjacobi@gmail.com

fracalanza, Ana Paula. Universidade de São Paulo. São Paulo, Brasil. fracalan@usp.br

Fonte: ELABORADO PELO AUTOR, 2018

$\checkmark$ Quanto ao ano de publicação $\rightarrow$ Percebe-se que o assunto tem sido estudado pelos pesquisadores há pouco tempo, pois de acordo com a pesquisa o trabalho mais antigo é de 2006, figura 4.

Figura 4: Gráfico por Ano de Publicação

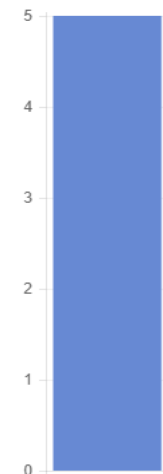

2017

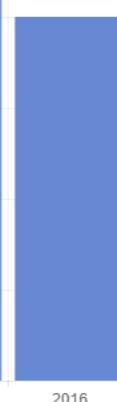

2016

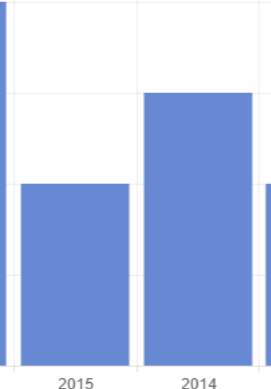

2014

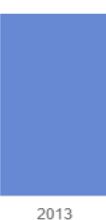

2013

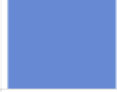

2012

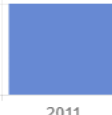

2011

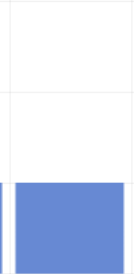

2010

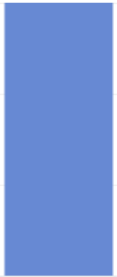

2008

Fonte: SCIELO.ORG, 2018 

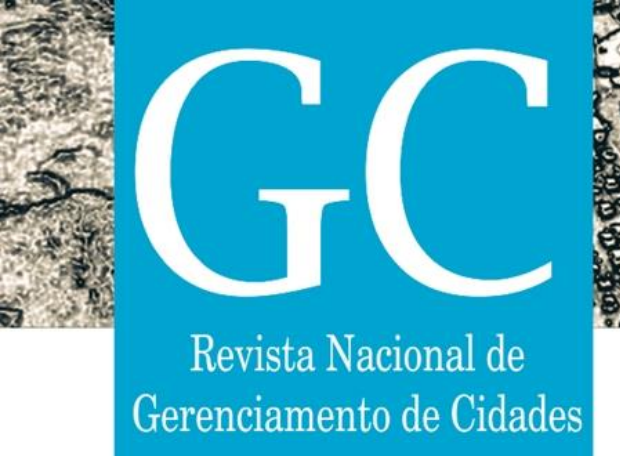

ISSN 2318-8472

v. 07, n. 51,2019

$\checkmark \quad$ Quanto ao idioma $\rightarrow$ Grande maioria dos artigos escritos em língua portuguesa (21 de $26=81 \%$ ) e mesmo entre os escritos em língua inglesa todos foram escritos por pesquisadores brasileiros, figura 5 .

Figura 5: Gráfico por Idioma de Publicação

25
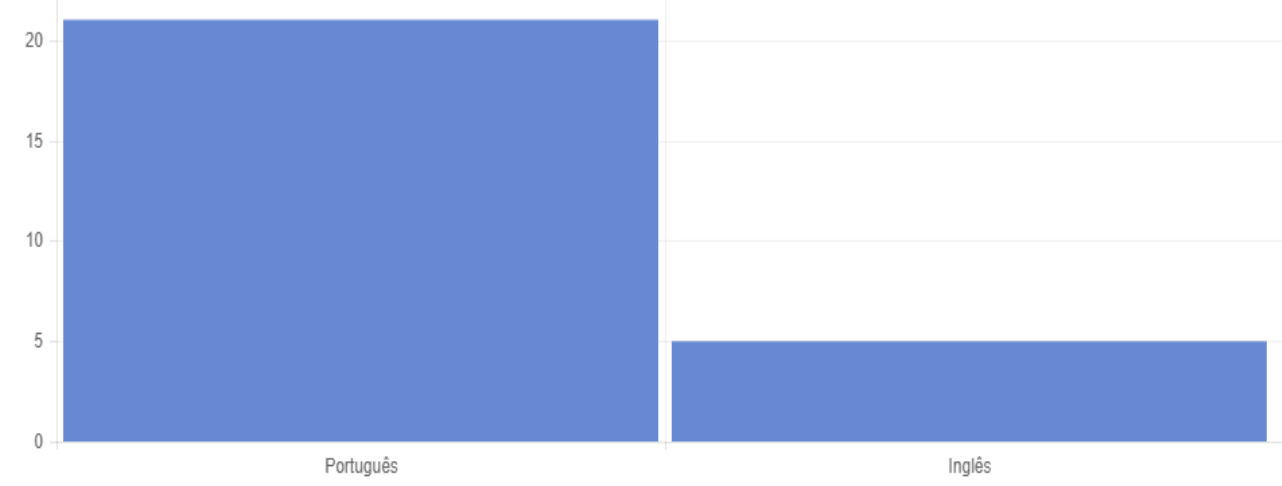

Fonte: SCIELO.ORG, 2018

Quanto ao periódico de publicação $\rightarrow$ Os trabalhos estavam distribuídos entre diversos periódicos com destaque para a Revista Estudos Avançados da USP que está classificada com o Qualis A2 da Plataforma Sucupira, figuras 6 e 7.

Figura 6: Gráfico de por Periódico de Publicação

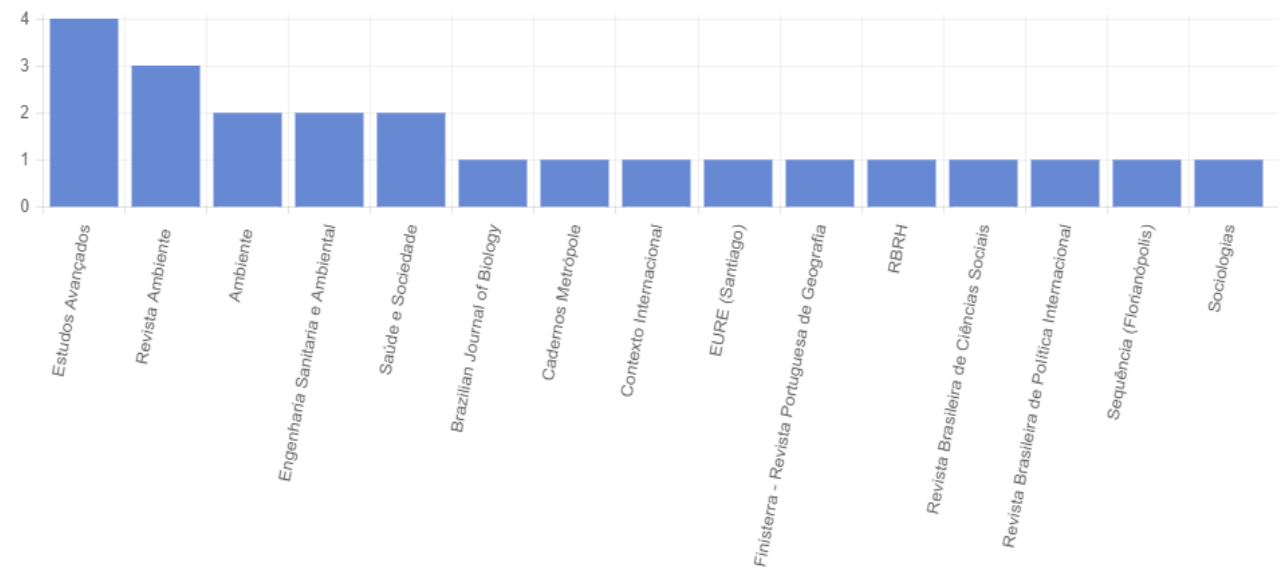

Fonte: SCIELO.ORG, 2018 


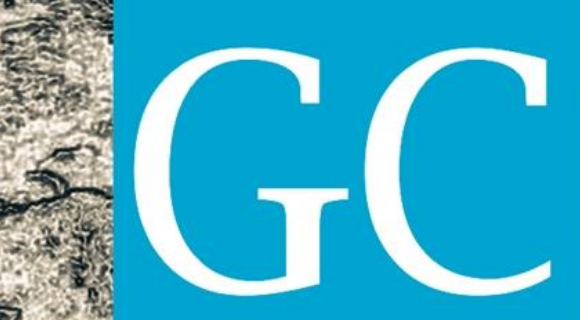

\section{Revista Nacional de}

Gerenciamento de Cidades

Figura 7: Classificação Qualis Plataforma Sucupira

\begin{tabular}{|c|c|c|c|}
\hline ISSN & Títilo & Áreade Araliaģio & Classificasion \\
\hline 1000.0592 & ESTUDOS AAANCGDOS (ONLLNE) & 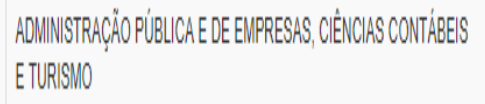 & A2 \\
\hline $0103-4014$ & ESTUDOS ANANCADOS (USP. IMPRESSO) & $\begin{array}{l}\text { ADUNISTRACGOAO PUBLLCA E EE ENPRESAS, CEENCLAS CONTABEES } \\
\text { ETURISNO }\end{array}$ & A2 \\
\hline
\end{tabular}

Fonte: SCIELO.ORG, 2018

Quanto à área temática $\rightarrow$ Os trabalhos foram classificados pela base de dados Scielo.org e em grande parte ( 12 de $26=46 \%$ ) estavam inseridos nas Ciências Humanas e em seguida a classificação Multidisciplinar ( 5 de 26 = 19\%), figura 8.

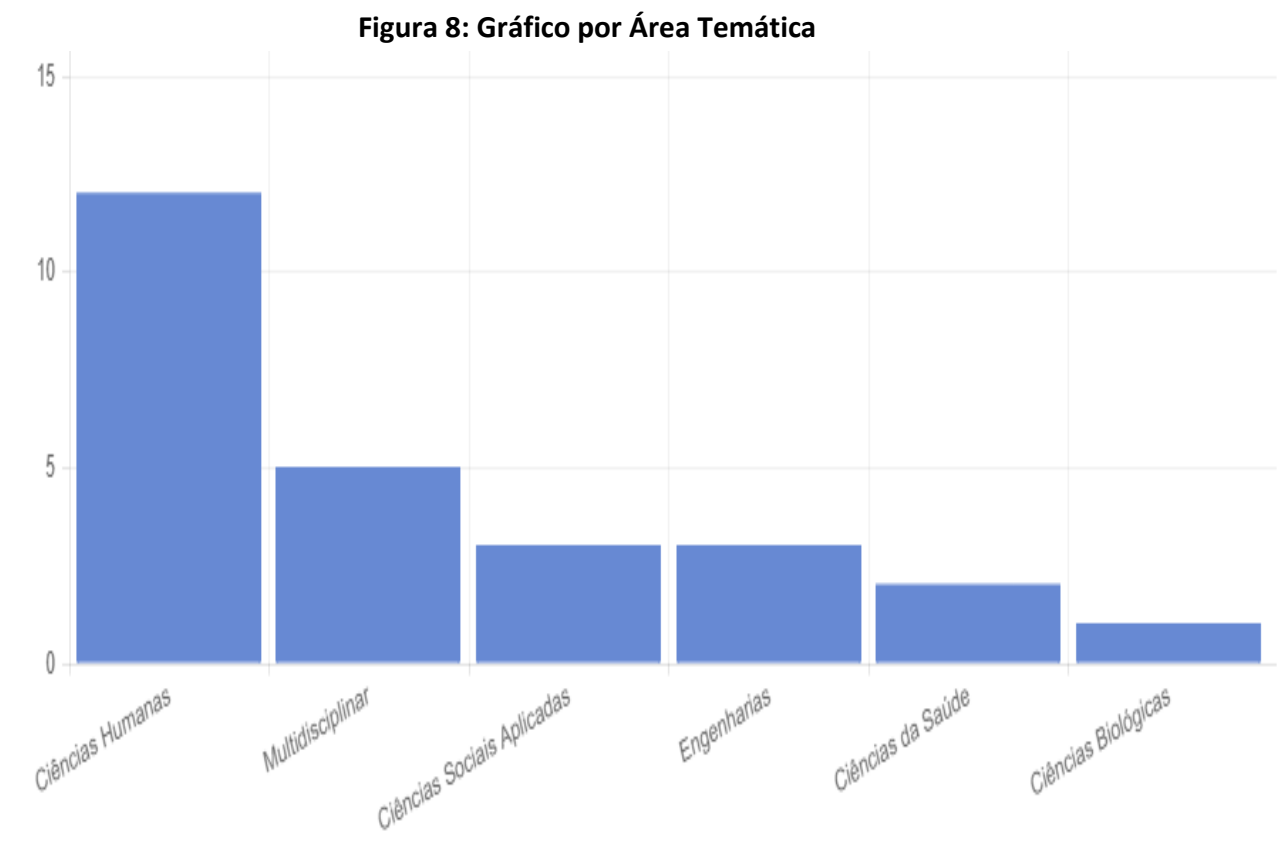

Fonte: SCIELO.ORG, 2018

\subsection{APRESENTAÇÃO DAS PRATICAS}

A partir da análise dos trabalhos foi possível também identificar as práticas relativas a cada um dos conceitos relacionadas a governança, o que nos permite conhecer as ações que vão além da teoria e da literatura sobre o tema.

\subsubsection{Práticas de Governança}




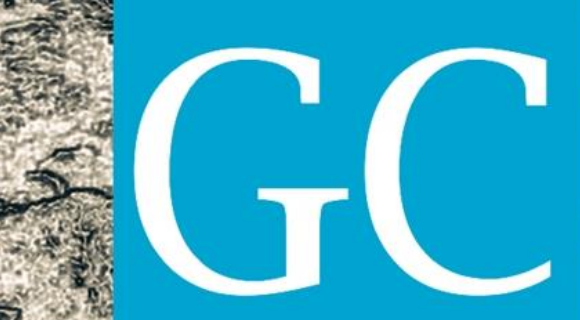

Revista Nacional de

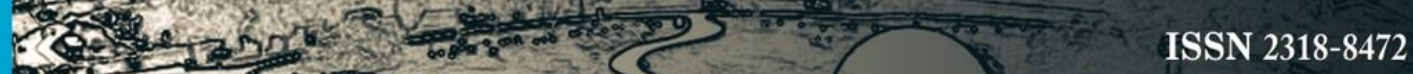

ISSN 2318-8472

v. 07, n. 51, 2019

Gerenciamento de Cidades

$\checkmark \quad$ Mudar as dietas alimentares, procurando produtos com pegada hídrica menor e que satisfaçam as necessidades nutricionais do ser humano;

$\checkmark \quad$ Reavaliar hábitos consumistas, adquirindo produtos e serviços que agridam menos o meio ambiente;

$\checkmark \quad$ Selecionar plantas e gramas nativas para jardins e paisagismo que dependam apenas das chuvas;

$\checkmark \quad$ Instalar aparelhos e utensílios mais eficientes, em termos de água e energia;

$\checkmark \quad$ Implementar práticas de reuso de água, em algumas atividades domésticas;

$\checkmark \quad$ Participar de comissões locais de gestão da água.

\subsubsection{Práticas de Pagamentos por Serviços Ambientais}

Um dos exemplos mais bem sucedidos de pagamento por serviços ambientais é o Projeto Conservador das Águas que foi lançado em 2003 pela Prefeitura de Extrema - MG com o apoio da Agência Nacional de Águas - ANA e o The Nature Conservancy - TNC, organização sem fins lucrativos que trabalha pela preservação do meio ambiente.

Para demonstrar a importância do programa, vamos conhecer um pouco do município e seu papel no abastecimento de água de milhões de pessoas em São Paulo, pois de acordo com o Instituto Brasileiro de Geografia e Estatística - IBGE (2010) a cidade de Extrema conta com uma população de aproximadamente 28.600 habitantes e ocupa uma área de $244,575 \mathrm{~km}^{2}$, está localizado no extremo sul de Minas Gerais, a $408 \mathrm{~km}$ de Belo Horizonte e a $100 \mathrm{~km}$ de São Paulo. Junto com Camanducaia, Itapeva e Toledo, também em Minas Gerais, é responsável por dois terços de volume de água destinado ao Sistema Cantareira para o abastecimento da Grande São Paulo como descrito por Whately e Cunha (2007).

A figura 1 mostra a localização do município e os limites de bacias hidrográficas. 


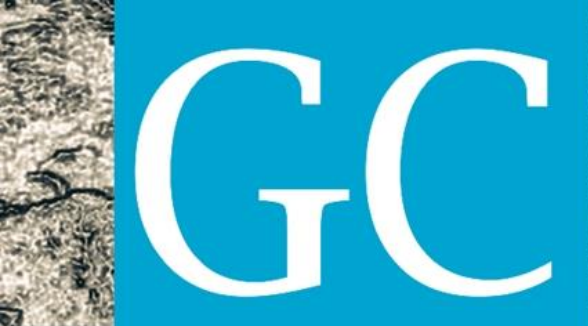

\section{Revista Nacional de}

Gerenciamento de Cidades
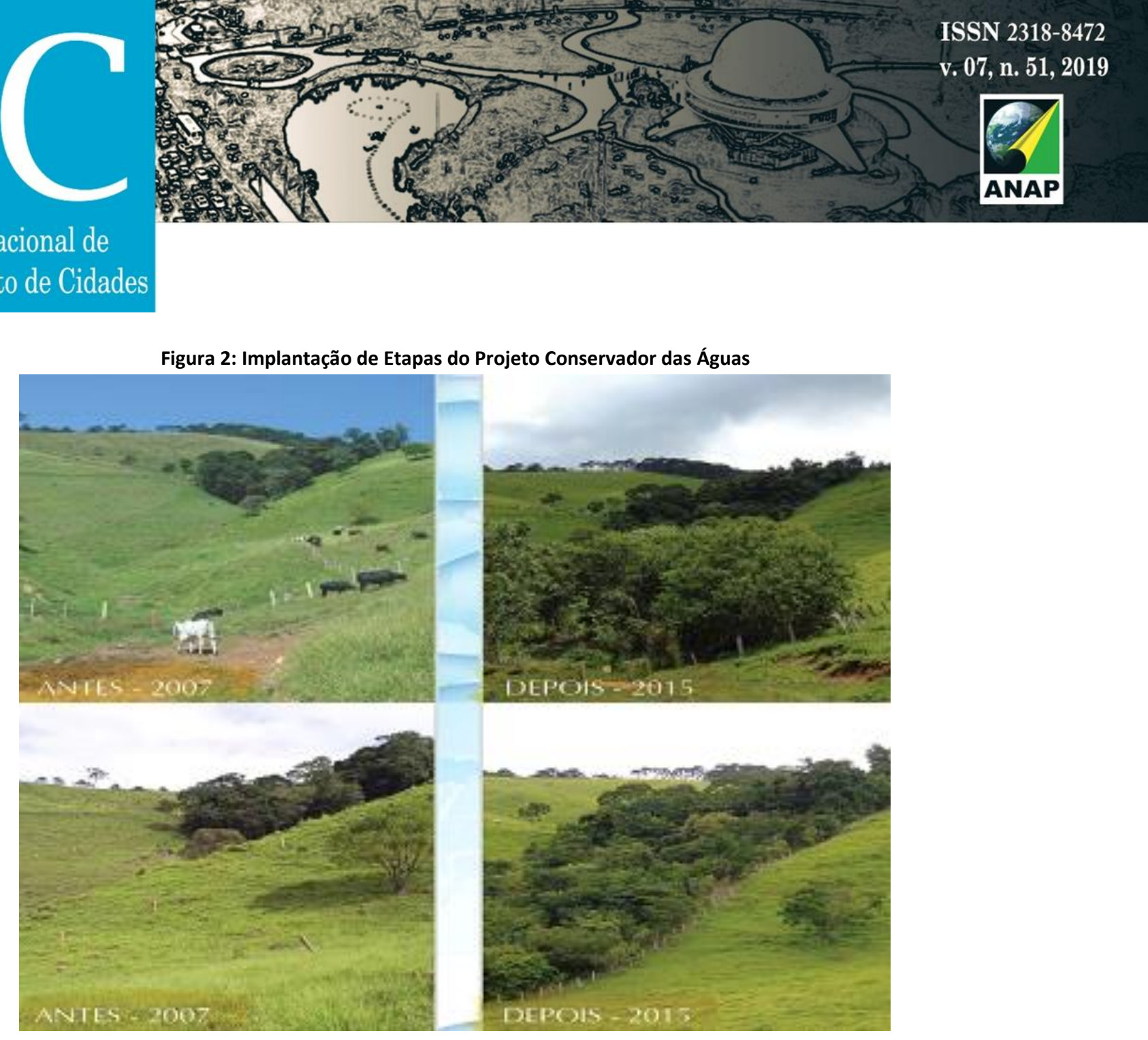

Fonte: Prefeitura de Extrema, 2016

\section{CONSIDERAÇÕES FINAIS}

Com base nos dados da pesquisa é possível constatar que ainda há pouco material sobre o tema da governança de recursos hídricos e que apenas nos últimos dez anos é que o número de trabalhos acadêmicos relacionados vem aumentando. A questão da escassez hídrica tem se tornado um problema cada vez mais próximo da população, vide a crise de 2014 e 2015 que gerou transtornos principalmente na região sudeste do Brasil.

Considerando a necessidade de buscar alternativas de mitigação dos impactos da escassez hídrica é urgente que soluções alternativas sejam pesquisadas e implantadas e ações de governança sejam discutidas entre o poder público, o setor privado e a sociedade garantindo que as decisões tomadas estejam dentro do que é considerado nas relações democráticas.

\section{REFERENCIAS}

BISSACOT, T.C.C.; OLIVEIRA, S.M.A.C. Development of management Tool for Water Risk Assessment (FARH): application in the mineral metallurgical segment in Brazil. 2017. Revista Brasileira de Recursos Hídricos.

BRASIL. Câmara dos Deputados. Relatório Instrumentos de Gestão das Águas - IGA. 2015. Centro de Documentação e Informação. Edições Câmara. 

